\title{
Association of phosphodiesterase 4D gene polymorphisms with chronic obstructive pulmonary disease: Relationship to interleukin 13 gene polymorphism
}

\author{
SHINSUKE HOMMA ${ }^{1}$, TOHRU SAKAMOTO ${ }^{1}$, AHMED E. HEGAB ${ }^{1}$, WATARU SAITOH ${ }^{1}$, AKIHIRO NOMURA ${ }^{1}$, \\ YUKIO ISHII $^{1}$, YUKO MORISHIMA ${ }^{1}$, TAKASHI IIZUKA ${ }^{1}$, TAKUMI KIWAMOTO ${ }^{1}$, YOSUKE MATSUNO ${ }^{1}$, \\ HOSAM H. MASSOUD ${ }^{2}$, HOSNY M. MASSOUD ${ }^{2}$, KHALID M. HASSANEIN ${ }^{2}$ and KIYOHISA SEKIZAWA ${ }^{1}$ \\ ${ }^{1}$ Department of Pulmonary Medicine, Institute of Clinical Medicine, Graduate School of Comprehensive Human Sciences \\ and University Hospital, University of Tsukuba, 1-1-1 Tennoudai, Tsukuba, Ibaraki 305-8575, Japan; ${ }^{2}$ Department \\ of Chest Diseases and Tuberculosis, Faculty of Medicine, Cairo University, El. Manyal, Cairo, Egypt
}

Received May 12, 2006; Accepted July 11, 2006

\begin{abstract}
Activation of the cyclic AMP (cAMP) signaling pathway leads to the suppression of inflammation in the airways and relaxation of airway smooth muscle. Intracellular cAMP levels are determined by a balance between the activities of adenylate cyclase and phosphodiesterases. We hypothesized that polymorphisms of the phosphodiesterase 4D (PDE4D) gene activate its protein function which leads to the downregulation of cAMP, resulting in the development of chronic obstructive pulmonary disease (COPD). A casecontrol study was performed using Japanese (96 COPD patients and 61 controls) and Egyptians (106 COPD patients and 72 controls) to investigate the association between the polymorphisms of the PDE4D gene and the development of COPD. Genotyping of all subjects for SNP7 (dbSNP ID, rs10075508), SNP13 (rs829259) and SNP15 (rs702531) in exon 15 of the PDE4D gene was conducted. Furthermore, the distributions of haplotypes consisting of PDE4D polymorphisms and those of interleukin (IL) 4, IL13 and $\beta_{2}$ adrenoceptor were analyzed. The distribution of SNP13 allele frequencies of the PDE4D gene was significantly different between the COPD and control groups in the Japanese population $(\mathrm{p}=0.041)$. In haplotype analysis, haplotypes composed of PDE4D SNP7 and IL13 +2044 G/A in the Japanese population showed significant difference between the patients and controls
\end{abstract}

Correspondence to: Dr Tohru Sakamoto, Department of Pulmonary Medicine, Institute of Clinical Medicine, Graduate School of Comprehensive Human Sciences and University Hospital, University of Tsukuba, 1-1-1 Tennoudai, Tsukuba, Ibaraki 305-8575, Japan

E-mail: t-saka@md.tsukuba.ac.jp

Key words: chronic obstructive pulmonary disease, haplotype, interleukin 13, linkage disequilibrium, phosphodiesterase 4, polymorphism $\left(\mathrm{p}_{\text {corr }}=0.00048\right)$. Thus, SNP13 and haplotypes, SNP7 G/A and IL13 + $2044 \mathrm{G} / \mathrm{A}$, may be useful for predicting COPD susceptibility.

\section{Introduction}

Chronic obstructive pulmonary disease (COPD) is characterized by slowly progressive airflow limitation, which arises from an abnormal inflammatory response of the lungs to noxious particles or gases, in particular, cigarette smoke. COPD is a multi-factorial complex disease. The development of COPD depends on the interactions of genetic factors and environmental effects. There is evidence for the involvement of genetic factors in COPD. First, COPD susceptibility due to cigarette smoke is different among individuals. Although nearly $90 \%$ of COPD patients are smokers (1), only $15 \%$ of smokers develop clinically significant COPD (2). Second, familial aggregation of the disease has been demonstrated (3). Third, there are differences in the prevalence of COPD among different ethnic groups (4). It is recognized that the genetic component of the disease consists of multiple genes, each of which has only a small influence, rather than a single Mendelian gene. To date, more than 30 polymorphisms of the candidate genes have been reported to be associated with COPD.

Cyclic AMP (cAMP) is a key second messenger in the signaling cascades controlling a variety of cellular functions and plays an important role in the pathogenesis of COPD. The activation of cAMP signaling inhibits $\mathrm{T}$ cell activation and proliferation (5), pro-inflammatory cytokine production (6), and recruitment of monocytes and neutrophils $(7,8)$. The relaxation of airway smooth muscle is also controlled by cAMP signaling (9). Intracellular cAMP levels are regulated by a balance between the rate of production and degradation. Phosphodiesterases (PDEs) are a sole family of enzymes that hydrolyze cAMP to 5'-AMP. They are classified into 11 major families (PDE1-11). Among them, PDE4 is a cAMPspecific enzyme localized in airway smooth muscle and epithelial cells as well as inflammatory cells $(9,10)$. A 
selective PDE4 inhibitor attenuates lung inflammation and prevents emphysema induced by cigarette smoke (11). PDE4 is composed of four isoforms, PDE4A, B, C and D. Approximately $50 \%$ of total PDE activity in the lung is accounted for by PDE4D (12). It has been demonstrated that the airways of PDE4D-deficient mice are refractory to cholinergic stimulation, that is, loss of contraction of the airway smooth muscle by the acetylcholine receptor agonist as well as loss of airway hyperresponsiveness (AHR) to the cholinergic agonist $(9,12)$. Inhalable anticholinergic drugs are widely used for the management of COPD. All of this evidence supports the possibility of PDE4D involvement in the development of COPD.

In this study, we hypothesized that polymorphisms of the PDE4D gene activate its protein function which leads to the downregulation of cAMP, resulting in the development of COPD. We performed a case-control association study to assess the association between the polymorphisms of the PDE4D gene and COPD susceptibility in two different ethnic groups, Japanese and Egyptian. The PDE4D gene is located on chromosome $5 q$ where interleukin (IL) 4 , IL13 and $\beta_{2}$ adrenoceptor (ADRB2) genes exist. Previously, we conducted a case-control study investigating the association of polymorphisms of IL4, IL13 and ADRB2 genes with COPD (13). Therefore, we studied pairwise haplotype frequencies consisting of polymorphisms of the PDE4D gene and those of IL4, IL13 and ADRB2 genes, and analyzed the association of the haplotype frequencies with the development of COPD.

\section{Materials and methods}

Study populations. We designed a case-control study of unrelated subjects with and without COPD in two different ethnic groups, Japanese and Egyptian. All the subjects were chronic heavy smokers with a Brinkman's index (the number of cigarettes/day $x$ the number of years) of $>450$. The Japanese subjects, 96 COPD patients and 61 controls, were recruited from Tsukuba University Hospital. The Egyptian subjects, 106 COPD patients and 72 controls, were recruited from Cairo University and affiliated hospitals. Ethnic and geographic matching was considered to eliminate the possible effect of population stratification. All subjects and their parents were born in the region of recruitment and had grandparents born in that country. COPD was diagnosed in all patients according to the criteria of the Global Initiative for Chronic Obstructive Lung Disease (14), and the forced expiratory volume in one sec $(\mathrm{FEV} 1)$ /forced vital capacity $(\mathrm{FVC})$ ratio was $<70 \%$. For the COPD group, those with FEV $1>70 \%$ predicted were excluded in order to eliminate subjects with mild airflow limitation. Subjects with a history of bronchial asthma, bronchiectasis, or other significant respiratory diseases were excluded. Controls were age- and smoking historymatched healthy subjects with normal pulmonary function. Written informed consent was obtained from all subjects and the study was approved by the ethics committees of the hospitals involved.

Genotyping. The genomic organization and the nucleotide sequence of PDE4D are shown in Nucleotide (accession number: NT_006713) on the National Center for Biotechnology
Information (NCBI) website (http://www. ncbi.nlm.nih.gov/). We searched the dbSNP database (http://www.ncbi.nlm.nih. gov/SNP/) in the NCBI for polymorphisms in exons of the PDE4D gene. Sixteen single nucleotide polymorphisms (SNPs) and four deletion/insertion polymorphisms (DIPs) were reported (Table I). Four polymorphisms (SNP1, SNP2, SNP3 and SNP4) are located in the coding region, and the remaining polymorphisms are in the 3'-untranslated region. One of the coding SNPs, SNP2, is a nonsynonymous polymorphism.

Genomic DNA was extracted from whole blood using a Qiagen DNA blood kit (Qiagen, Hilden, Germany). For 5 patients and 5 controls in each ethnic group, we screened PCR-DNA fragments covering the polymorphisms by DNA sequencing in order to check their minor allele frequencies. As rare polymorphisms are less likely to play a major role in disease pathogenesis and require a very large number of subjects to show enough power, genotyping of all subjects was performed only for polymorphisms showing minor allele frequencies more than $20 \%$ in either ethnic group in the initial screening step. Genotyping of all the subjects for SNP7, SNP13 and SNP15 was determined by TaqMan allelic discrimination (Applied Biosystems, CA, USA). We used ready-made primer-probe mixtures for SNP7 (TaqMan SNP genotyping assay ID: C__2435128_10) and SNP15 (assay ID: C_2435134_10). For SNP13, a pair of primers flanking the SNP and a pair of oligonucleotide probes, one homologous to the wild-type labeled with 6-carboxyfluorescein (FAM) and another homologous to the mutant type labeled with VIC, were designed and synthesized by Applied Biosystems. The forward primer was 5'-CCTGAGTGAAGTCTAGAAAGAA AGGTAAA-3' and the reverse primer was 5'-CATTATTA AGATTCTAGGCACTCTGTGGG-3'. The probes were 5'[VIC]CTCCTCCCTACACTTAGT[MGB]-3' and 5'-[FAM] CTCCTCCCTACTCTTAGT[MGB]-3'. The PCR was carried out on $20 \mathrm{ng}$ of genomic DNA in a $25 \mu \mathrm{l}$ reaction containing $900 \mathrm{nM}$ of each forward and reverse primer, $200 \mathrm{nM}$ of each FAM and VIC probe, and 1x TaqMan Universal PCR Master Mix (Applied Biosystems). PCR cycling conditions in the ABI PRISM 7000 (Applied Biosystems) were as follows: $50^{\circ} \mathrm{C}$ for $2 \mathrm{~min}, 95^{\circ} \mathrm{C}$ for $10 \mathrm{~min}$, followed by 40 cycles of $95^{\circ} \mathrm{C}$ for $15 \mathrm{sec}$ and $60^{\circ} \mathrm{C}$ for $1 \mathrm{~min}$. Allelic discrimination was determined by the fluorescence intensity of FAM and VIC.

Statistical analysis. Statistical analysis of clinical profiles between COPD patients and control subjects was performed by unpaired t-test. Significance was accepted at $\mathrm{p}<0.01$. Hardy-Weinberg equilibrium was assessed using a goodnessof-fit $\chi^{2}$ test for biallelic markers. Statistical analysis of the genotype and allele frequencies between the patients and controls was calculated using $\chi^{2}$ contingency table analysis with the appropriate number of degrees of freedom. Odds ratios (ORs) and $95 \%$ confidence intervals (CIs) were calculated to quantitatively assess the degree of association observed. Statistical significance was defined as $p<0.05$. We did not adopt Bonferroni's correction for multiple comparisons in the analysis of the genotype and the allele frequencies of PDE4 polymorphisms since the individual alleles studied were in strong linkage disequilibrium.

We have reported the association of polymorphisms of IL4, IL13 and ADRB2 genes with COPD in Japanese and 
Table I. Polymorphisms in the PDE4D gene.

\begin{tabular}{lcccc}
\hline Polymorphism & dbSNP ID & Exon & Function & Allele \\
\hline SNP1 & rs17853589 & 14 & coding (synonymous) & G/A \\
SNP2 & rs1058458 & 15 & coding (nonsynonymous) & coding (synonymous) \\
SNP3 & rs1058459 & 15 & coding (synonymous) & G/A \\
SNP4 & rs7736186 & 15 & 3'-UTR & G/A \\
DIP1 & rs10718401 & 3'-UTR & C/T \\
SNP5 & rs12187668 & 15 & 3'-UTR & $(-$ )/TTTA \\
DIP2 & rs3839219 & 15 & 3'-UTR & $(-$ )/TTGT \\
DIP3 & rs3839218 & 15 & 3'-UTR & -)/TTCT \\
DIP4 & rs3839217 & 15 & 3'-UTR & A/G \\
SNP6 & rs17719258 & 15 & 3'-UTR & G/A \\
SNP7 & rs10075508 & 15 & 3'-UTR & A/G \\
SNP8 & rs829260 & 15 & 3'-UTR & C/T \\
SNP9 & rs10940636 & 15 & 3'-UTR & G/T \\
SNP10 & rs12658211 & 3'-UTR & A/G \\
SNP11 & rs10036063 & 15 & 3'-UTR & T/C \\
SNP12 & rs10035437 & 15 & 3'-UTR & A/T \\
SNP13 & rs829259 & 15 & 3'-UTR & C/T \\
SNP14 & rs13172038 & 15 & 3'-UTR & 3'-UTR \\
SNP15 & rs702531 & 15 & 15 & G/A \\
SNP16 & rs702530 & 15 & 15 & \\
\hline SNP & & 15 & \\
\end{tabular}

SNP, single nucleotide polymorphism; DIP, deletion/insertion polymorphism; UTR, untranslated region.

Egyptians (13). These polymorphisms are IL4 -589 C/T, -33 C/T and a variable number of 70 -bp tandem repeats (VNTR) in intron 3 of IL4, $-1111 \mathrm{C} / \mathrm{T}$ and $+2044 \mathrm{G} / \mathrm{A}$ in IL13, and $+46 \mathrm{~A} / \mathrm{G}$ and $+79 \mathrm{C} / \mathrm{G}$ in ADRB2. All the Japanese (88 COPD patients and 61 controls) and Egyptian subjects (106 COPD patients and 72 controls) in the previous report were included in this study. For these subjects, Lewontin's disequilibrium coefficient $\mathrm{D}^{\prime}(15)$ and a squared correlation coefficient value $\left(\mathrm{r}^{2}\right)$ were used to measure linkage disequilibrium between two polymorphisms of the PDE4D, IL4, IL13 and ADRB2 genes. In the same way, pairwise haplotype frequencies were estimated using the expectation-maximization algorithm with SNPAlyze program (Dynacom, Mobara, Japan). Haplotype distributions for the COPD and control groups were assessed by Fisher's exact test using 2x4 tables. Bonferroni's correction was applied to correct for multiple testing. A corrected $\mathrm{p}$ value $\left(\mathrm{p}_{\text {corr }}\right)<0.05$ was considered significant.

\section{Results}

Characteristics of the subjects are shown in Table II. Most of the subjects in the Japanese population and all in the

Table II. Clinical features of the study populations.

\begin{tabular}{|c|c|c|c|c|c|c|}
\hline & \multicolumn{3}{|c|}{ Japanese } & \multicolumn{3}{|c|}{ Egyptians } \\
\hline & COPD & Control & $\mathrm{p}$ value & COPD & Control & $\mathrm{p}$ value \\
\hline Subjects (n) & 96 & 61 & & 106 & 72 & \\
\hline Sex, M/F (n) & $92 / 4$ & $60 / 1$ & & $106 / 0$ & $72 / 0$ & \\
\hline Age (years) & $68.0 \pm 1.0$ & $67.8 \pm 1.2$ & NS & $62.5 \pm 0.9$ & $59.0 \pm 1.0$ & NS \\
\hline Brinkman's index & $1252.8 \pm 75.3$ & $1066.6 \pm 61.4$ & NS & $1050.0 \pm 60.3$ & $990.9 \pm 69.6$ & NS \\
\hline FVC \%pred (\%) & $77.7 \pm 2.4$ & $97.1 \pm 2.5$ & $<0.001$ & $56.3 \pm 1.0$ & $92.3 \pm 0.9$ & $<0.001$ \\
\hline $\mathrm{FEV}_{1}(\mathrm{l})$ & $1.0 \pm 0.1$ & $2.5 \pm 0.1$ & $<0.001$ & $0.9 \pm 0.03$ & $2.8 \pm 0.04$ & $<0.001$ \\
\hline $\mathrm{FEV}_{1} \%$ pred $(\%)$ & $46.8 \pm 1.3$ & $96.2 \pm 2.6$ & $<0.001$ & $30.3 \pm 1.1$ & $85.9 \pm 0.4$ & $<0.001$ \\
\hline $\mathrm{FEV}_{1} / \mathrm{FVC}(\%)$ & $43.4 \pm 1.3$ & $81.4 \pm 1.3$ & $<0.001$ & $44.3 \pm 1.2$ & $78.3 \pm 1.0$ & $<0.001$ \\
\hline
\end{tabular}

NS, not significant. Brinkman's index is the number of cigarettes/day $x$ the number of years. Data are presented as the mean \pm SEM. 
Egyptian population were male. This was due to the social reason that most heavy smokers are male in both countries. Age and Brinkman's index were not significantly different between the patient and control groups. All the patients in both ethnic groups had moderate to severe COPD.

In the initial screening step, four polymorphisms in the coding region (SNP1, SNP2, SNP3 and SNP4), and two polymorphisms in the 3'-UTR (SNP5 and DIP3) were wild-type homozygous for all subjects studied. Two polymorphisms, SNP6 and SNP8, had minor allele frequencies $<10 \%$ in both ethnic groups. These eight polymorphisms were excluded from the next study for genotyping all of the subjects. The remaining 12 polymorphisms showed minor allele frequencies $>20 \%$ in both ethnic groups. Under the condition of minor allele frequency of $20 \%$ and a significance level of 0.05 , the sample size in this study offered more than $80 \%$ power to detect a significant association with the relative risk of 2.5 calculated by the Power Calculator (http://calculators.stat. ucla.edu/). These 12 polymorphisms were divided into three groups, in which the affiliated polymorphisms were in complete linkage disequilibrium. The first group was composed of 9 polymorphisms, DIP1, DIP2, DIP4, SNP7, SNP9, SNP10, SNP11, SNP12 and SNP14. The second group had only one polymorphism, SNP13. The third group consisted of 2 polymorphisms, SNP15 and SNP16. One polymorphism from each group was selected for the next study,
SNP7 from the first group, SNP13 from the second group, and SNP15 from the third group. All the subjects in both ethnic groups were genotyped for these three polymorphisms.

Table III shows the genotype and allele frequencies of SNP7, SNP13 and SNP15 in both COPD patients and controls. All the genotypes of the COPD patients and controls in both ethnic groups conformed to expectations based on Hardy-Weinberg analysis. Of these three polymorphisms, a significant difference was detected in the distribution of allele frequencies of SNP13 in the Japanese population. The frequency of the major allele $\mathrm{T}$ in the COPD group was significantly higher than that in the Japanese control group by a $2 \times 2$ allele frequency table $(\mathrm{p}=0.041, \mathrm{OR}=1.63,95 \%$ $\mathrm{CI}=1.02-2.62$ ). A $2 \times 2$ allele positivity table also showed that the frequency of COPD patients without allele A of SNP13 $(\mathrm{T} / \mathrm{T})$ was significantly higher than with allele $\mathrm{A}(\mathrm{A} / \mathrm{A}$ and $\mathrm{A} / \mathrm{T})(\mathrm{p}=0.043, \mathrm{OR}=2.01,95 \% \mathrm{CI}=1.02-3.99)$; however, there was no deviation in the distribution of genotype frequencies by a $3 \times 2$ contingency table. As for SNP7 and SNP15, the distributions of both genotype and allele frequencies were not significantly different between the patient and control groups in either population. Since the three polymorphisms were in strong linkage disequilibrium, correction for multiple comparisons was not adopted for these analyses.

The results of the linkage disequilibrium analysis between SNP7, SNP13 and SNP15 in Japanese and Egyptians are

Table III. Genotype and allele frequencies of SNP7, SNP13 and SNP15.

\begin{tabular}{|c|c|c|c|c|c|c|c|}
\hline \multirow{2}{*}{\multicolumn{2}{|c|}{ Polymorphism }} & \multicolumn{3}{|c|}{ Japanese } & \multicolumn{3}{|c|}{ Egyptians } \\
\hline & & $\begin{array}{l}\text { COPD } \\
\text { n }(\%)\end{array}$ & $\begin{array}{c}\text { Control } \\
\mathrm{n}(\%)\end{array}$ & $\mathrm{p}$ value & $\begin{array}{l}\text { COPD } \\
\text { n }(\%)\end{array}$ & $\begin{array}{c}\text { Control } \\
\mathrm{n}(\%)\end{array}$ & $\mathrm{p}$ value \\
\hline \multirow[t]{7}{*}{ SNP7 } & Genotype & & & \multirow{4}{*}{ NS } & & & \multirow{4}{*}{ NS } \\
\hline & $\mathrm{G} / \mathrm{G}$ & $63(66)$ & $36(59)$ & & $84(80)$ & $58(81)$ & \\
\hline & $\mathrm{G} / \mathrm{A}$ & $28(29)$ & $22(36)$ & & $21(20)$ & $14(19)$ & \\
\hline & $\mathrm{A} / \mathrm{A}$ & $4(4)$ & $3(5)$ & & $0(0)$ & $0(0)$ & \\
\hline & \multicolumn{6}{|l|}{ Allele } & \\
\hline & G & $154(81)$ & $94(77)$ & NS & $189(90)$ & $130(90)$ & \multirow[t]{2}{*}{ NS } \\
\hline & A & $36(19)$ & $28(23)$ & & $21(10)$ & $14(10)$ & \\
\hline \multicolumn{7}{|c|}{ SNP13 Genotype } & \multirow{4}{*}{ NS } \\
\hline & $\mathrm{A} / \mathrm{A}$ & $11(12)$ & $11(18)$ & \multirow[t]{3}{*}{ NS } & $14(13)$ & $10(14)$ & \\
\hline & $\mathrm{A} / \mathrm{T}$ & $40(42)$ & $31(52)$ & & $46(43)$ & $33(46)$ & \\
\hline & $\mathrm{T} / \mathrm{T}$ & $44(46)$ & $18(30)$ & & $46(43)$ & $28(39)$ & \\
\hline \multicolumn{7}{|c|}{ Allele } & \multirow{3}{*}{ NS } \\
\hline & A & $62(33)$ & $53(44)$ & 0.041 & $74(35)$ & $53(37)$ & \\
\hline & $\mathrm{T}$ & $128(67)$ & $67(56)$ & & $138(65)$ & $89(63)$ & \\
\hline \multicolumn{7}{|c|}{ SNP15 Genotype } & \multirow{4}{*}{ NS } \\
\hline & $\mathrm{T} / \mathrm{T}$ & $11(12)$ & $11(19)$ & \multirow[t]{3}{*}{ NS } & $10(9)$ & $8(11)$ & \\
\hline & $\mathrm{T} / \mathrm{G}$ & $42(44)$ & $30(51)$ & & $40(38)$ & $29(40)$ & \\
\hline & $\mathrm{G} / \mathrm{G}$ & $42(44)$ & $18(31)$ & & $56(53)$ & $35(49)$ & \\
\hline \multicolumn{7}{|c|}{ Allele } & \multirow{3}{*}{ NS } \\
\hline & $\mathrm{T}$ & $64(34)$ & $52(44)$ & \multirow[t]{2}{*}{ NS } & $60(28)$ & $45(31)$ & \\
\hline & G & $126(66)$ & $66(56)$ & & $152(72)$ & 99 (69) & \\
\hline
\end{tabular}

NS, not significant. Some subjects could not be genotyped for technical reasons. 
Table IV. Linkage disequilibrium between SNP7, SNP13 and SNP15 in Japanese and Egyptians.

\begin{tabular}{lrccc}
\hline & & $\mathrm{D}^{\prime}$ & $\mathrm{r}^{2}$ & $\mathrm{p}$ \\
\hline Japanese & SNP7:SNP13 & 1.000 & 0.441 & $<0.001$ \\
& SNP7:SNP15 & 1.000 & 0.434 & $<0.001$ \\
Egyptians & SNP13:SNP15 & 1.000 & 0.973 & $<0.001$ \\
& SNP7:SNP13 & 1.000 & 0.305 & $<0.001$ \\
& SNP7:SNP15 & 1.000 & 0.351 & $<0.001$ \\
& SNP13:SNP15 & 0.984 & 0.831 & $<0.001$ \\
\hline
\end{tabular}

D', Lewontin's disequilibrium coefficient value; $\mathrm{r}^{2}$, squared correlation coefficient value.

summarized in Table IV. It has been suggested that a $\mathrm{D}^{\prime}$ value of $>0.33$ or a $\mathrm{r}^{2}$ value of $>0.1$ is a criterion for useful linkage disequilibrium $(16,17)$. Strict linkage disequilibrium was detected between all pairs of SNPs in both ethnic groups. Since the PDE4D gene is located on chromosome 5q12, and IL4, IL13 and ADRB2 genes are situated on chromosome 5q31-33, the linkage disequilibrium between polymorphisms in the PDE4D gene and those in IL4, IL13 and ADRB2 genes was analyzed (Tables V and VI). Interestingly, PDE4D SNP7 was in strong linkage disequilibrium with the IL13 $+2044 \mathrm{G} / \mathrm{A}$ polymorphism in both ethnic groups, although the $5 \mathrm{q} 12$ portion is far from $5 \mathrm{q} 31$. In the Japanese, PDE4D SNP13 and SNP15 were also in significant linkage disequilibrium with IL13 +2044 G/A, and PDE4D SNP7 was in tight linkage disequilibrium with IL13 -1111 C/T. In the Egyptians, PDE4D SNP15 was in significant linkage disequilibrium with IL13 +2044 G/A and IL4 VNTR.

Pairwise haplotype frequencies using all of the polymorphisms were estimated separately for the patients and controls in both ethnic groups. Haplotypes consisting of two polymorphisms of IL4, IL13 and ADRB2 genes were excluded since they had been previously reported (13). The distributions of the remaining haplotype frequencies were tested for association with COPD. The $\mathrm{p}$ values for the haplotype frequencies were corrected for 24 comparisons. In the Japanese population, the distribution of the haplotype composed of SNP7 G/A and IL13 +2044 G/A was significantly different between the COPD and control groups $\left(\mathrm{p}_{\text {corr }}=0.00048\right)$ (Table VII). Eleven percent of the Japanese controls displayed PDE4D SNP7 A : IL13 +2044 A, while none of the COPD patients had this haplotype. In the Egyptian population, no significant difference was detected in the distribution of this haplotype between patient and control groups. The distributions of the other haplotype frequencies were not significantly different between the patients and controls in both ethnic groups.

\section{Discussion}

A large number of polymorphisms have been reported in the genomic DNA of the PDE4D gene, most of which are situated in the introns. We selected only polymorphisms located in the exons, since it is thought that polymorphisms in exons are more likely to change protein functions than those in introns. The PDE4D gene has at least 8 isoforms, all of which have an identical C-terminal domain, but the $\mathrm{N}$ terminal region is unique for each isoform. These isoforms are created by the presence of different promoters and

Table V. Linkage disequilibrium between the SNPs of the PDE4D gene and polymorphisms in IL4, IL13 and ADRB2 genes in Japanese.

\begin{tabular}{lcccccccc}
\hline & & IL4 -589 & IL4 -33 & IL4 VNTR & IL13 -1111 & IL13 +2044 & ADRB2 +46 & ADRB2 +79 \\
\hline SNP7 & D' $^{\prime}$ & 0.153 & 0.148 & 0.348 & 1.000 & 1.000 & 0.064 & 0.031 \\
& $\mathrm{r}^{2}$ & 0.004 & 0.004 & 0.015 & 0.066 & 0.099 & 0.001 & $<0.001$ \\
& $\mathrm{p}$ & 0.380 & 0.517 & 0.141 & $<0.001$ & $<0.001$ & 0.514 & 0.898 \\
SNP13 & $\mathrm{D}^{\prime}$ & 0.146 & 0.131 & 0.287 & 0.183 & 0.483 & 0.070 & 0.184 \\
& $\mathrm{r}^{2}$ & 0.007 & 0.006 & 0.021 & 0.004 & 0.047 & 0.002 & 0.006 \\
& $\mathrm{p}$ & 0.324 & 0.378 & 0.054 & 0.383 & 0.007 & 0.568 & 0.461 \\
SNP15 & $\mathrm{D}^{\prime}$ & 0.135 & 0.121 & 0.272 & 0.170 & 0.467 & 0.063 & 0.302 \\
& $\mathrm{r}^{2}$ & 0.006 & 0.005 & 0.020 & 0.004 & 0.046 & 0.002 & 0.015 \\
& $\mathrm{p}$ & 0.370 & 0.422 & 0.072 & 0.304 & 0.004 & 0.599 & 0.071 \\
\hline
\end{tabular}

D', Lewontin's disequilibrium coefficient value; $\mathrm{r}^{2}$, squared correlation coefficient value. 
Table VI. Linkage disequilibrium between the SNPs of the PDE4D gene and polymorphisms in IL4, IL13 and ADRB2 genes in Egyptians.

\begin{tabular}{lcrrccccc}
\hline & & IL4 -589 & IL4 -33 & IL4 VNTR & IL13 -1111 & IL13 +2044 & ADRB2 +46 & ADRB2 +79 \\
\hline SNP7 & D $^{\prime}$ & 0.120 & 0.248 & 0.375 & 0.179 & 0.999 & 0.284 & 0.093 \\
& $\mathrm{r}^{2}$ & $<0.001$ & 0.004 & 0.004 & 0.001 & 0.022 & 0.006 & 0.003 \\
& $\mathrm{p}$ & 0.434 & 0.264 & 0.330 & 0.656 & 0.005 & 0.172 & 0.300 \\
SNP13 & $\mathrm{D}^{\prime}$ & 0.012 & 0.024 & 0.021 & 0.027 & 0.250 & 0.097 & 0.064 \\
& $\mathrm{r}^{2}$ & $<0.001$ & $<0.001$ & $<0.001$ & $<0.001$ & 0.007 & 0.003 & 0.002 \\
& $\mathrm{p}$ & 0.915 & 0.714 & 0.884 & 0.640 & 0.128 & 0.241 & 0.416 \\
SNP15 & $\mathrm{D}^{\prime}$ & 0.029 & 0.029 & 0.349 & 0.002 & 0.368 & 0.161 & 0.060 \\
& $\mathrm{r}^{2}$ & $<0.001$ & $<0.001$ & 0.013 & $<0.001$ & 0.011 & 0.007 & 0.003 \\
& $\mathrm{p}$ & 0.880 & 0.880 & 0.030 & 0.994 & 0.047 & 0.096 & 0.324 \\
\hline
\end{tabular}

D', Lewontin's disequilibrium coefficient value; $\mathrm{r}^{2}$, squared correlation coefficient value.

Table VII. Haplotype frequencies with significantly different distributions between the COPD and control groups in Japanese.

\begin{tabular}{|c|c|c|c|c|c|}
\hline \multicolumn{3}{|c|}{ Haplotype } & \multirow{2}{*}{$\begin{array}{l}\text { COPD } \\
\text { n (\%) }\end{array}$} & \multirow{2}{*}{$\begin{array}{c}\text { Control } \\
\text { n (\%) }\end{array}$} & \multirow{2}{*}{$\begin{array}{c}\begin{array}{c}\mathrm{p} \text { value } \\
\left(\mathrm{p}^{\text {corr }}\right)\end{array} \\
0.00002\end{array}$} \\
\hline SNP7 & G : IL13 +2044 & G & & & \\
\hline & A & G & $36(20)$ & $15(12)$ & $(0.00048)$ \\
\hline & G & A & $49(28)$ & $27(22)$ & \\
\hline & A & A & $0(0)$ & $13(11)$ & \\
\hline
\end{tabular}

alternative splicing (18). In this study, polymorphisms in the putative promoters were not examined. All the polymorphisms examined in this study were in the 3 '-end region of the PDE4D gene, that is, in exon 14 and exon 15 .

Of the 20 polymorphisms studied, only SNP13 in the Japanese population showed a significant difference in the distribution of allele frequency as well as allele positivity between COPD and control groups. SNP13 is located in the 3'-untranslated region, and although it does not alter PDE4D protein structurally, it is possible that the polymorphism exerts an influence on protein function by changing the rate of translation by modifying mRNA stability and/or ribosome binding (19). It has been demonstrated that PDE4D expression is regulated by mRNA stability (20). It is also possible that SNP13 is in linkage disequilibrium with an original causal polymorphism which has not been identified in or near the PDE4D gene.

This study demonstrated that the minor allele A frequency of SNP13 was higher in the controls than in the COPD patients in Japanese. Thus, it is thought that the nucleotide substitution from $\mathrm{T}$ to $\mathrm{A}$ of SNP13 plays a protective role in susceptibility to COPD. Since the frequency of COPD patients without allele $A$ in the Japanese population was significantly higher than those with allele A by a $2 \times 2$ allele positivity table, it is thought that the protective effect of allele A works dominantly.
We previously performed a case-control study to assess the association of polymorphisms of IL4, IL13 and ADRB2 genes with the development of COPD (13). The IL4, IL13 and ADRB2 genes are located on chromosome 5q31-33, and the PDE4D gene is located on chromosome 5q12. IL4, IL13 and ADRB2 are associated with AHR $(21,22)$. IL4 and IL13 are also known to induce mucous production $(23,24)$. As for the PDE4D gene, specific PDE4 inhibitors attenuate AHR (25) and suppress airway mucus production (26). AHR is one of the risk factors for COPD mortality (27) and airway mucous production is a major symptom of COPD. Furthermore, one of the mechanisms by which $\beta_{2}$ adrenergic agonists induce airway smooth muscle relaxation is through the cAMPprotein kinase A phosphorylation cascade pathway (28). Therefore, in this study, we calculated the linkage disequilibrium between polymorphisms of the PDE4D gene and those of IL4, IL13 and ADRB2 genes. Although the PDE4D gene is approximately $70 \mathrm{M}$ base pair apart from the IL13 gene, tight linkage disequilibrium was detected between PDE4D SNP7 and IL13 +2044 G/A across the ethnicities. This result suggests that these two polymorphisms may work cooperatively on the development of COPD, and pairwise haplotype analysis consisting of these two polymorphisms showed significant difference between the cases and controls in the Japanese population. Haplotype analysis has greater statistical power than analyzing individual polymorphisms independently. 
We speculate that polymorphisms with high genotype relative risk are conserved across ethnicities. However, it is desirable that the associations between polymorphisms and phenotypes are confirmed in independent populations to exclude the possibility of spurious associations. We analyzed an Egyptian population, which is geographically and genetically different from the Japanese. In this study, the statistically significant differences detected in the Japanese population could not be replicated in the Egyptian population. Although this discrepancy might be due to type I error, there are some possible explanations. Since COPD is a multifactorial disease with environmental and genetic factors involved in its etiology, it is possible that different polymorphisms in different ethnic groups under different environmental conditions cause the same COPD phenotype. Furthermore, COPD is a heterogeneous disorder including airway inflammation and destruction of lung parenchyma, both of which lead to progressive airflow limitation. Therefore, different polymorphisms may be responsible for each distinct condition of COPD.

In conclusion, this study suggested the association of SNP13 of the PDE4D gene and the haplotypes composed of PDE4D SNP7 and IL13 +2044 G/A with COPD susceptibility in a Japanese population. These SNP and haplotypes might be useful for predicting COPD susceptibility, thus preventing disease progression by early intervention.

\section{References}

1. Snider GL: Chronic obstructive pulmonary disease: risk factors, pathophysiology and pathogenesis. Annu Rev Med 40: 411-429, 1989.

2. Bascom R: Differential susceptibility to tobacco smoke: possible mechanisms. Pharmacogenetics 1: 102-106, 1991.

3. Kueppers F, Miller RD, Gordon H, Hepper NG and Offord K: Familial prevalence of chronic obstructive pulmonary disease in a matched pair study. Am J Med 63: 336-342, 1977.

4. Marcus EB, Buist AS, Curb JD, MacLean CJ, Reed DM, Johnson LR and Yano K: Correlates of FEV1 and prevalence of pulmonary conditions in Japanese-American men. Am Rev Respir Dis 138: 1398-1404, 1988.

5. Skalhegg BS, Landmark BF, Doskeland SO, Hansson V, Lea T and Jahnsen T: Cyclic AMP-dependent protein kinase type I mediates the inhibitory effects of 3',5'-cyclic adenosine monophosphate on cell replication in human T lymphocytes. J Biol Chem 267: 15707-15714, 1992.

6. Torphy TJ: Phosphodiesterase isozymes: molecular targets for novel antiasthma agents. Am J Respir Crit Care Med 157: 351-370, 1998.

7. Fine JS, Byrnes HD, Zavodny PJ and Hipkin RW: Evaluation of signal transduction pathways in chemoattractant-induced human monocyte chemotaxis. Inflammation 25: 61-67, 2001.

8. Ariga M, Neitzert B, Nakae S, Mottin G, Bertrand C, Pruniaux MP, Jin SL and Conti M: Nonredundant function of phosphodiesterases $4 \mathrm{D}$ and $4 \mathrm{~B}$ in neutrophil recruitment to the site of inflammation. J Immunol 173: 7531-7538, 2004.

9. Mehats C, Jin SL, Wahlstrom J, Law E, Umetsu DT and Conti M: PDE4D plays a critical role in the control of airway smooth muscle contraction. FASEB J 17: 1831-1841, 2003.

10. Landells LJ, Szilagy CM, Jones NA, Banner KH, Allen JM, Doherty A, O'Connor BJ, Spina D and Page CP: Identification and quantification of phosphodiesterase 4 subtypes in CD4 and CD8 lymphocytes from healthy and asthmatic subjects. Br J Pharmacol 133: 722-729, 2001

11. Martorana PA, Beume R, Lucattelli M, Wollin L and Lungarella G: Roflumilast fully prevents emphysema in mice chronically exposed to cigarette smoke. Am J Respir Crit Care Med 172: $848-853,2005$.
12. Hansen G, Jin S, Umetsu DT and Conti M: Absence of muscarinic cholinergic airway responses in mice deficient in the cyclic nucleotide phosphodiesterase PDE4D. Proc Natl Acad Sci USA 97: 6751-6756, 2000.

13. Hegab AE, Sakamoto T, Saitoh W, Massoud HH, Massoud HM, Hassanein KM and Sekizawa K: Polymorphisms of IL4, IL13, and ADRB2 genes in COPD. Chest 126: 1832-1839, 2004.

14. Pauwels RA, Buist AS, Calverley PM, Jenkins CR and Hurd SS: GOLD Scientific Committee: Global strategy for the diagnosis, management, and prevention of chronic obstructive pulmonary disease. NHLBI/WHO Global Initiative for Chronic Obstructive Lung Disease (GOLD) Workshop summary. Am J Respir Crit Care Med 163: 1256-1276, 2001

15. Lewontin RC: On measures of gametic disequilibrium. Genetics 120: 849-852, 1988

16. Abecasis GR, Noguchi E, Heinzmann A, Traherne JA, Bhattacharyya S, Leaves NI, Anderson GG, Zhang Y, Lench NJ, Carey A, Cardon LR, Moffatt MF and Cookson WO: Extent and distribution of linkage disequilibrium in three genomic regions. Am J Hum Genet 68: 191-197, 2001.

17. Nakajima T, Jorde LB, Ishigami T, Umemura S, Emi M, Lalouel JM and Inoue I: Nucleotide diversity and haplotype structure of the human angiotensinogen gene in two populations. Am J Hum Genet 70: 108-123, 2002.

18. Gretarsdottir S, Thorleifsson G, Reynisdottir ST, Manolescu A, Jonsdottir S, Jonsdottir T, Gudmundsdottir T, Bjarnadottir SM, Einarsson OB, Gudjonsdottir HM, Hawkins M, Gudmundsson G, Gudmundsdottir H, Andrason H, Gudmundsdottir AS, Sigurdardottir M, Chou TT, Nahmias J, Goss S, Sveinbjornsdottir S, Valdimarsson EM, Jakobsson F, Agnarsson U, Gudnason V, Thorgeirsson G, Fingerle J, Gurney M, Gudbjartsson D, Frigge ML, Kong A, Stefansson K and Gulcher JR: The gene encoding phosphodiesterase 4D confers risk of ischemic stroke. Nat Genet 35: 131-138, 2003.

19. Kozak M: How strong is the case for regulation of the initiation step of translation by elements at the 3 ' end of eukaryotic mRNAs? Gene 343: 41-54, 2004.

20. Liu H, Palmer D, Jimmo SL, Tilley DG, Dunkerley HA, Pang SC and Maurice DH: Expression of phosphodiesterase 4D (PDE4D) is regulated by both the cyclic AMP-dependent protein kinase and mitogen-activated protein kinase signaling pathways. A potential mechanism allowing for the coordinated regulation of PDE4D activity and expression in cells. J Biol Chem 275: 26615-26624, 2000

21. Venkayya R, Lam M, Willkom M, Grunig G, Corry DB and Erle DJ: The Th2 lymphocyte products IL-4 and IL-13 rapidly induce airway hyperresponsiveness through direct effects on resident airway cells. Am J Respir Cell Mol Biol 26: 202-208, 2002.

22. D'amato M, Vitiani LR, Petrelli G, Ferrigno L, di Pietro A, Trezza R and Matricardi PM: Association of persistent bronchial hyperresponsiveness with beta2-adrenoceptor (ADRB2) haplotypes. A population study. Am J Respir Crit Care Med 158: 1968-1973, 1998

23. Dabbagh K, Takeyama K, Lee HM, Ueki IF, Lausier JA and Nadel JA: IL-4 induces mucin gene expression and goblet cell metaplasia in vitro and in vivo. J Immunol 162: 6233-6237, 1999.

24. Whittaker L, Niu N, Temann UA, Stoddard A, Flavell RA, Ray A, Homer RJ and Cohn L: Interleukin-13 mediates a fundamental pathway for airway epithelial mucus induced by CD4 T cells and interleukin-9. Am J Respir Cell Mol Biol 27: 593-602, 2002.

25. Kanehiro A, Ikemura T, Makela MJ, Lahn M, Joetham A, Dakhama A and Gelfand EW: Inhibition of phosphodiesterase 4 attenuates airway hyperresponsiveness and airway inflammation in a model of secondary allergen challenge. Am J Respir Crit Care Med 163: 173-184, 2001.

26. Mata M, Sarria B, Buenestado A, Cortijo J, Cerda M and Morcillo EJ: Phosphodiesterase 4 inhibition decreases MUC5AC expression induced by epidermal growth factor in human airway epithelial cells. Thorax 60: 144-152, 2005.

27. Hospers JJ, Postma DS, Rijcken B, Weiss ST and Schouten JP: Histamine airway hyper-responsiveness and mortality from chronic obstructive pulmonary disease: a cohort study. Lancet 356: 1313-1317, 2000.

28. Johnson M: The beta-adrenoceptor. Am J Respir Crit Care Med 158: S146-S153, 1998. 